\title{
Boyu Zhang
}

\section{Chinese Music and Ethnomusicology}

This article is based on introduction of my dissertation Numerical Rhythmic Structure of Chinese Percussion Music - An analytical Study of Shifan Luogu Collections.

\section{A. Chinese musical resources}

It is widely recognised that the content of China's music is richly intertwined with folklore musical traditions widely practised in China. This is inevitable, in view of the many historical events that have shaped the country's cultural evolution to the state that it is today. In this regard, Chinese music research could be considered as being one of the most important branches of ethnomusicology in the world.

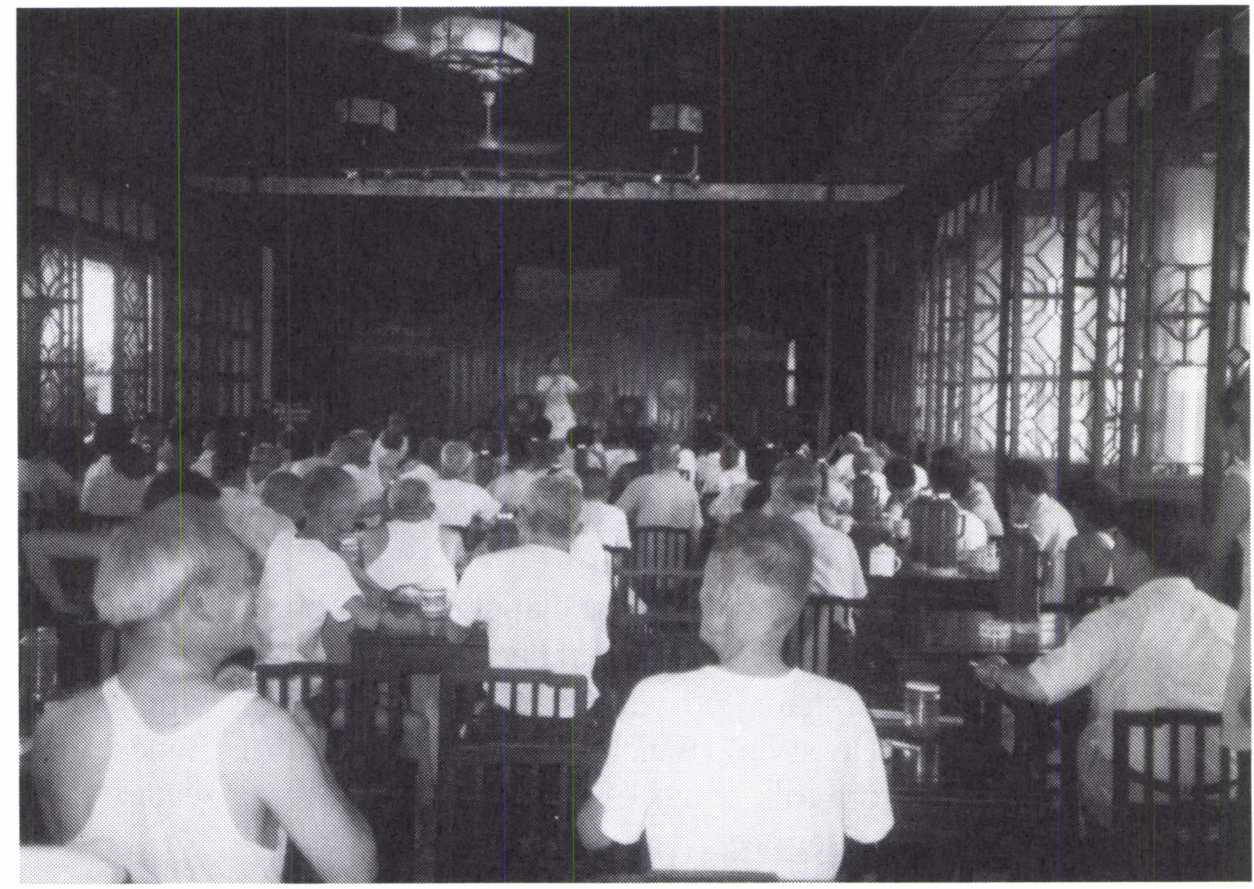

Picture 1. A tea house in Suzhou. Different types of musical performances are always given to the tea drinkers. Photograph by Boyu Zhang. 
In present-day China, there are rich sources not only for musical history in general, but also for folk music in particular. Such resources are a living and fascinating object of study both for Chinese and Western scholars. ${ }^{1}$ According to Chinese musicological theory, this folk music can be classified into five categories, namely instrumental music, opera music, narrative music, dancing music and folk songs. (Chinese Music Institute 1990.)

\section{a. Instrumental Music}

Chinese instrumental music could be divided into two categories: solo and ensemble. The solo instrumental music could be further categorised as follows: bowed-strings (Gongxuan), plucked-strings (Tanbo), wind (Cuiguan), and percussion (Daji) instruments. Scholars have traditionally been more interested in bowed, plucked, and wind instrumental genres of music, such as the di (bamboo flute), pipa (the pear-shaped lute with four strings), qin (seven-stringed plucked zither), erhu (two-stringed fiddle with hollow wooden cylindrical sound box), and so on.

Similarly, ensemble music could also be further categorised as music for string ensemble (Xиаnsuo Yue), string-bamboo flute ensemble (Sizu Yue), drumwind ensemble (Gucui Yue), wind-percussion ensemble (Cuida Yue) and percussion ensemble (Luogu Yue). The five types of ensemble are described in the introduction above, and represent the main traditions of Chinese music.

\section{b. Opera Music}

There are more than three hundred local operas in different areas of China. Chinese opera could be categorised into four types on musical criteria:

(1). Pi Huang (skin and yellow), which is an abbreviated form derived from the combination of the two names: Xipi (western skin) and Erhuang (two yellows), each of which is recognised as an autonomous form in the Beijing opera.

(2). Bang $Z i$ (clapper), which is also called clapper opera, after the main rhythmic instrument, a percussion instrument called the "clapper". Qiqiang, which is popular around the Shaanxi province, is an example of this category.

(3). Kun Qiang (Kun melo-style), which is the oldest form of Chinese opera music. It is derived from folk songs of Kunshan in Jiangsu province. Kunqu opera belongs to this category.

\footnotetext{
${ }^{1}$ For more references, please see B. "Chinese Music Research", pp. 234.
} 
(4). Kao Qiang (high melo-style), which is popular in the south-west of China, especially in Sichuan, Jiangxi and Hunan provinces. The main feature of $\mathrm{KaO}$ Qiang is that of a chorus added at the end of solo phrases. The Chuan opera, which is popular in Sichuan province, is an instance of this category.

\section{c. Narrative Music}

China seems to be considered as a country with a very rich narrative tradition. The term "narrative music" here refers to the type of music which is called Quyi in Chinese. The main characteristic of this genre is that the story is sung. According to a preliminary investigation done by Chinese Music Institute (Chinese Music Institute, 1990), there are more than two hundred different types of narrative music in China. They are divided into eight categories:

(1). Gu Ci (drum and song), which is popular in the north of China. A singer plays a shu drum (a dish-shaped drum having both sides covered by skin) and sings a story with accompaniment by a small orchestra.

(2). Tan $\mathrm{Ci}$ (plucked and song), which is popular in the south of China. One or two singers sing a story, simultaneously themselves playing on the pipa or sanxian (a three-stringed lute with a long, fretless neck and an oval-shaped sound box which are both sides covered by snake skin).

(3). $Y u G u$ (Yu drum), which is popular in Hubei, Hunan, Guangxi and Henan provinces. A singer accompanies himself on a $y u$ drum (thick bamboo stick drum having one side covered by skin).

(4). Paizi Qu (labeled tunes), which is popular in Shandong, Shanxi and Guangxi provinces. A singer sings a story accompanied by a small orchestra.

(5). Qin Su (strings and song), which is popular in Beijing, Shandong, Sichuan and Yunnan provinces. Singing is accompanied on the yangqin (dulcimer) and other instruments.

(6). Zhou Chang (walking and singing), which is popular everywhere in China. The famous Zhou Chang are Fengyang Huagu of Anhue province, Sanbang $G u$ of Hubei province, and Panci and Chedeng of Sichuan province.

(7). $\mathrm{Za} Q u$ (miscellaneous), which music derived from folk songs. One or two melodies are often repeated several times. Examples include Shidao from Tiangjin city, and Lianhua Luo from Zhejiang province.

(8). Ban Yong (clapper and song), which is a special oral tradition in which the musical element is minimal. The words are recited in a regular rhythm, accompanied on the clapper.

\section{d. Folk Song Music}

Folk songs always seem to play an important role as the foundation or musical 
database for any type of folk music. There is a great number of folk songs available in China, in view of the country's large population and vast area. Generally, Chinese folk songs could be divided into three categories:

(1). Mountain Songs (Shange). This category is used in a general sense to refer to songs popular in the countryside, especially in the mountain areas.

(2). Ditties (Xiaodiao). There are many ditties in China; they are especially popular in the cities, and the contents of the songs are closely interrelated with urban life. Consequently, ditties are often called city songs.

(3). Work songs (Laodong Gequ). Before industrialisation, much work was carried out by hand, and work songs were used to help people to work together.

\section{e. Folk Dancing Music}

\section{(1). Folk dances in the South or West of China}

Yang Ge (field dance), which is popular north of the Yellow River, in the north, east and north-east of China.

$Y a o G u$ (dancing drums), which is a dance where the drum is worn against the dancer's waist and beaten while dancing. It is popular in North or West of China.

Paohan Chuan (the boat runs on the road): a "boat", made of cloth, is placed around the middle of the dancer's body, so that the lower part of the dancer's body is under the boat, and the upper part is on the boat. The dancer runs so as to imitate the boat's movement on the water.

(2). Folk dances of the South or East of China

Hua Deng (flower lamp): which is popular in the southwest of China. There are two dancers, a man who holds a fan, and a woman who holds a handkerchief.

Cai Cha (pick tea), which is very popular in the provinces of south of China that are called "the home of tea". Three people can dance together, imitating the actions of the tea pickers.

\section{f. Historical resources}

The historical resources of music in China are extremely large. Generally, these resources can be classified into four categories: musical instruments, books, paintings and sculptures, and musical notations.

As the well-known violinist Yehudi Menuhin noticed Chinese archaeologists 
have already found a big number of ancient musical instruments in China. ${ }^{2}$ Several types of xun, one of the oldest Chinese instruments which probably developed from hunting tool and created in the Neolithic Age $(100,000-7000$ BC), has already been found, for example, stone xun which was pear-shaped, tube-shaped or fish-shaped, pottery xun with holes numbering from one to three. Animal bone whistles were also found from archaeological sites of the Hemudu culture which probably dates back 7000 years. Until the Zhou dynasty $(1,100$ $71 \mathrm{BC})$, there were about seventy musical instruments, which were classified into eight types based on material: metal, stone, pottery, skin, gourd, silk, wood, and bamboo. This might be the first classification of musical instruments in the human history. Many of the Chinese musical instruments whether they were preserved, such as qin and pipa from Tang dynasty (618 - 907), or unearthed, such as chime bells from Zenghouyi tomb (5th century BC), have formed a remarkable part of the Chinese music research.

From times dating back to ancient China, musical study has played an important role in the pursuance of academic interests. There were many ancient writings about musical study, both independent volumes and entries in encyclopaedias and dynastic annals. The scholars who studied music in ancient China were mainly members of the literati, intellectuals who studied music as a vocation; but full-time professional and official studies were pursued as well. For example, two thousand years ago, the ruler of the monarchy established the Yuefu (music bureau) for musical events. The most important contribution of the Yuefu was that musicians were encouraged to collect folk songs from the countryside. This led to the collation of music from all over the countryside at $Y u e f u$, which has benefited both musicians and citizens.

According to Isabel Wong (1990), writings on Chinese ancient music can be classified under nine headings, as follows:

1. Yuexue (systematic and historical musicology)

2. Luxue (theories and methods for pitch calculation)

3. Writings on the Confucian or Taoist view of music

4. Records of court institutions of music in various dynasties

5. Bibliographical records of music repertoires

6. Anecdotes about well-known musicians and entertainers

7. Writings exploring the aesthetics and ideology of Qin music

8. Treatises on Kunqu music

9. Organological works

One can understand that such works or writings are now most important resources for the present day. Understanding these resources already is hard work.

\footnotetext{
${ }^{2}$ Yehudi Menuhin and Curtis W. Davis: The Music of Man, Macdonald General Books, Macdonald and Jane's Publishers Limited 1980: 1-47.
} 
Many scholars are investigating the books and endeavour to understand their real meaning.

Iconographical research is a new direction of the ethnomusicology. This kind of study is considered to be more important for the Chinese musical research. This is essentially because the resources of the iconography of music in China are very rich. Such iconographical resources contain paintings, whether in books or tombs or caves, and sculptures, which are mostly found in temples and caves. For example, in the Mokao Grottoes of Dunhuang, the location of an important town on the famous "silk road" at the western end of Hexi (west of the Yellow River) corridor in north-west Gansu province, there are 1.600 meters of paintings, many of them concerned with music. Findings from such iconographical resources are significant and beneficial for our study. A picture of a musical instrument, for instance, can give us information on the form of an instrument in a certain period, way of playing, use of the instrument, settings of the performance, and so forth. By comparing the pictures of the same instrument painted in different times, we can find how this instrument had changed in the ancient times. Pipa is a good example shown in the pictures of Dunhuang (see pictures 2 and 3$)$.

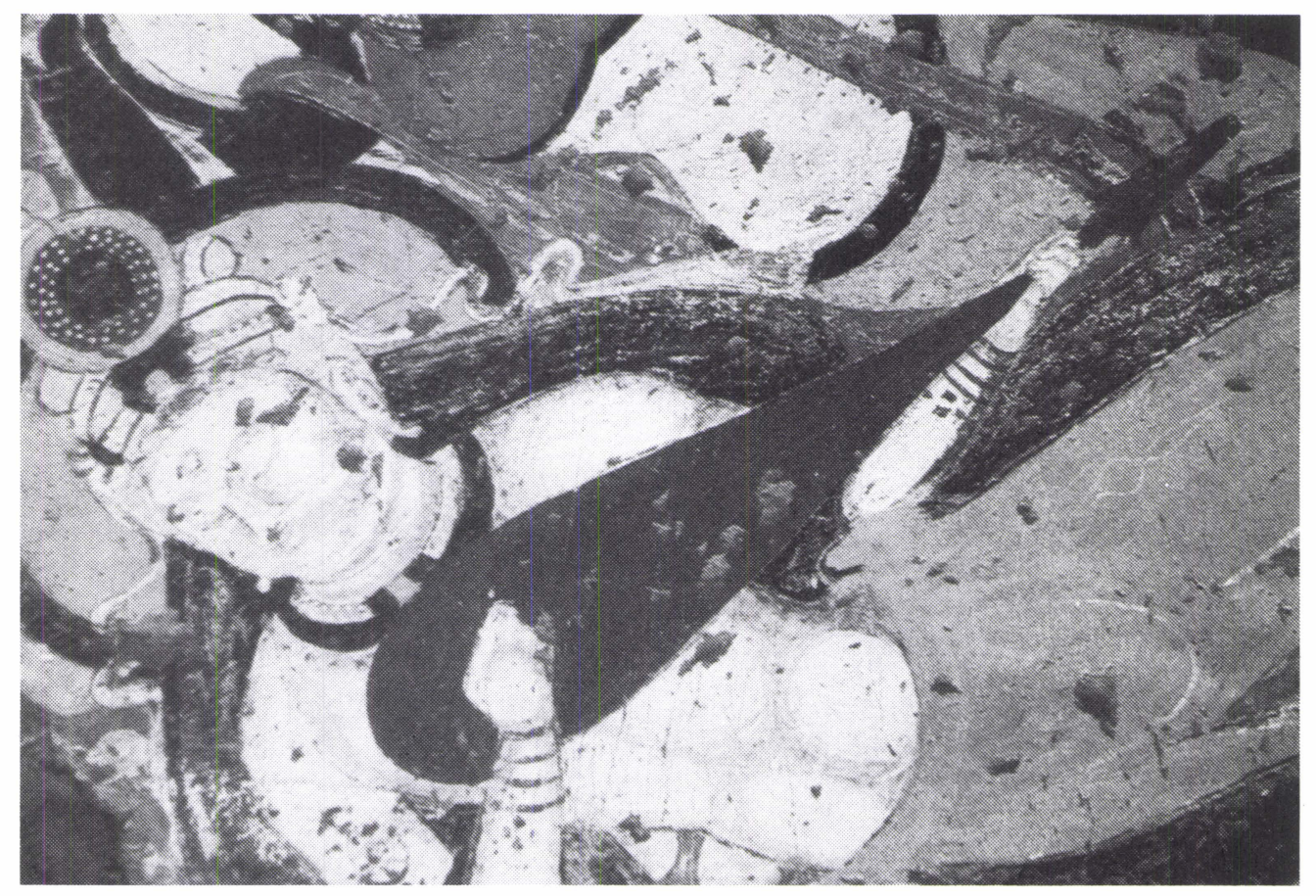

Picture 2. Pipa playing in northern Wei period (386-535). Photograph by Jiang Yongxing. ${ }^{3}$

${ }^{3}$ In China Supplementary Volume 1 Instruments. The Universe of Music - A history. A Unesco / IMC Project. Zhao Feng (Ed.), 1991. 


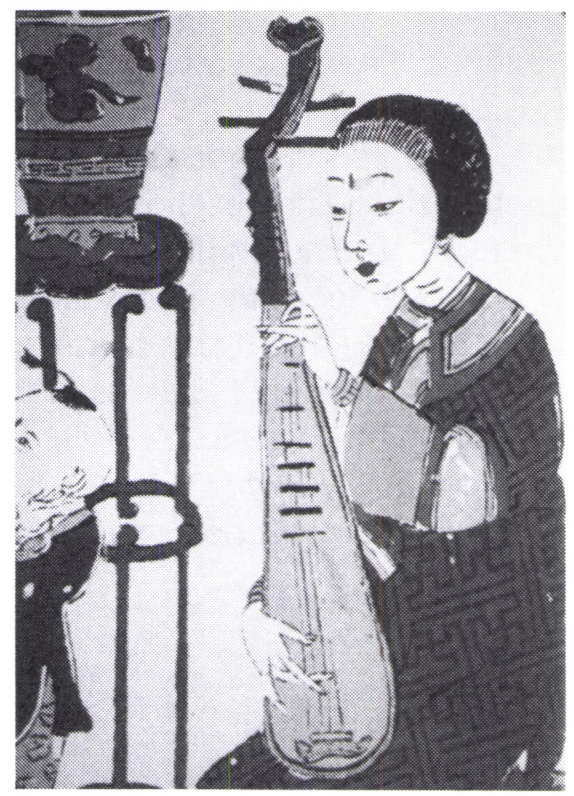

Picture 3. Pipa playing in Qing dynasty (1644-1911). Photography by Jiang Yongxing.

Notation study is a popular topic by the Chinese musicologists, since there are many old musical collections preserved in China. These collections are either instrumental or vocal, national or local. To draw a picture of the notations used by these collections is not easy task, due to the enormous size the collections. In order to draft a picture of the ancient Chinese notations, we may find these features useful: First, the notations are used in different systems. The tablature notation of qin seems to be the oldest one. Because qin was the favourite musical instrument of the ancient Chinese scholars, writing on qin, including the instrument itself and its music, is extremely large. Hundreds of volumes of music of qin have been collected and preserved. Secondly, "exotic musical notation" (Suyue $\mathrm{Pu}$ ) is another important type of ancient Chinese notation system. Notation of this type is significant because a large body of scores using this notation have been found, and because the meaning of the symbols used for notating has been lost. This type appeared before Tang dynasty and was preserved mainly in the Mokao Grottoes of Dunhuang. In the course of history, the meaning of such symbols has been lost. The present situation is that no one knows the real musical meaning of such symbols. Several scholars have tried to find the secrets of this notation. Two of the well-known explanations of this notation have been given by Ye Dong and Chen Ying-Shi, ${ }^{4}$ both are professors at the Conservatory

\footnotetext{
${ }^{4}$ Please see Ye Dong: "Study on the notation of Dunhuang" (Dunhuang Yuepu Yanjiu) and Chen Ying-Shi: "A Fresh Inquiry into the Dunhuang Manuscripts of Tang Dynasty Music", a report at the "International Colloquium on Chinese Music", held from 28th to 30th December, 1988, in Hong Kong.
} 
of Shanghai. The explanation given by Hayashi Kenzo and Hirade Hisao, two Japanese scholars, is also influential. ${ }^{5}$ Thirdly, Gongche notation, which was another system of notation, came into being in the Ming dynasty. This notation also used several Chinese characters as notes, however, the difference between Gongche notation and the tabulature notation of qin is that Gongche notation uses a few of Chinese characters to indicate pitches instead of pointing a place. Therefore, this notation can be used not only by instruments but also by vocals. Consequently, it was very popular for many hundreds years until Western cipher and staff notation was disseminated to China. "A Great Collection of Tunes on Nine Keys from North and South" (Jiugong Dachen Nanbei Cigong Pu), an important old Chinese vocal music collection, was collected in the Gongche notation.

\section{B. Chinese music research in China}

To illustrate the situation of music research in China is not without difficulties. Every year, a yearbook is published on China's music, including many reports selected for publication in the yearbook. Reports included are written by various scholars, divided into different topics, and report only the year's events. The following is an attempt to cover not the whole scope of situation of the current Chinese music research but only the main features.

\section{a. Achievements of the Chinese music research}

Since China has rich resources of both the history and present-day state of folk music, Chinese musicologists usually concentrate on these two aspects. In historical studies, scholars emphasise the systematic and historical musicology (Yuexue) ${ }^{6}$ theories and methods for pitch calculation (Luxue) and aesthetics, ${ }^{7}$ and in the study of present-day folk music, morphological investigation.

Folk songs are the most popular subjects of Chinese musical research. There

\footnotetext{
${ }^{5}$ Hayashi Kenzo and Hirade Hisao: "Study on the Ancient Transcriptions of Pipa" (Pipa Gupu Zhi Yanju), Originaly published in Japanese in 1938, Chinese translation by Yao Zhong-Yi has been published in the Art of Music, No. 2, 1987.

${ }^{6}$ For example, Yang Yin-Liu: "History of Chinese Ancient Music" (Zhongguo Gudai Yinyue Shi, 1981), Wu Chao and Liu Dong-Sheng: "Abbreviation of Chinese Music History" (Zhongguo Yinyue Shilue, 1983), Wang Yu-He: "History of Chinese Contemporary Music" (Zhongguo Jinxiandai Yinyue Shi), published by People's Music Publishing House in 1982.

7 See Huang Xiang-Peng: "Researching to the Origin: Study on the Chinese Traditional Music" (Suoyuan Tanyuan: Zhongguo Chuntong Yinyue Yangju), People's Music Publishing House, 1993.
} 
are several of scholars who are keen on the folk song research. Many of publications come into being each year from articles to books and collections. There are no difficulties to find folk song collections even that of a particular area, because every county or province has tried to collect and publish folk songs popular in their district, especially during the nineteen-sixties. The collections are the bases of research work, another words, the research work is continuous work of collecting, the situation of less research literature, which has been published, than collections is obvious, due the collections are treated as the final goals. There are, however, a few books worth of mentioning here. Prof. Song Da-Neng contributed his first publication on Chinese folk song research (Song Da-Neng 1979). Although this is a introductory work, it is still very popular among readers. "Introduction to the Folk songs of Han Nationality" (Hanzu Minge Gailun) is another important contribution. ${ }^{8}$ Prof. Jiang Ming-Dun, the author, was educated in Western music. Starting in 1958, he turned his focus on Chinese folk songs, and taught Chinese folk song music in Shanghai Conservatory of Music for many years. He collected hundreds of thousands of folk songs from different areas in China and worked on them for more than twenty years. In his book, he discussed different types of Chinese songs and their variations, the methods of expression, musical characteristics, melody, rhythm, mode, musical structure, style, as well as the relationships between the melody and words. This book was selected as the best text book for higher education by the Chinese Ministry of Education. Prof. Fan Zu-Yin has also published a book titled "General Introduction to the Chinese Multi Voiced Folk Songs" (Zhongguo Duoshengpu Minge Gailun).$^{9}$ This research focused mainly on the symptom of the multi voiced folk songs of twenty-three Chinese minorities, to study their different ways of singing, and different characteristics of the music regarding meter, rhythm, mode, and melody.

There is a large number of publication on the research of Chinese operas. Almost all the provincial operas have been studied by their specialists. Only in the publications of the Beijing opera and Kunqu opera, for example, will we get sufficient literature. "Introduction to Beijing Opera Music" (Jingju Yinyue Gailun, Liu Ji-Dian: 1993) is a significant book which every one who is concerned with Chinese music should read. He Wei, Prof. at the Chinese Opera Institute at the Chinese Academy of Arts, has published a number of collections on Beijing opera percussion music. These collections use different systems of notation, from traditional to modern. ${ }^{10}$ Prof. Wu Jun-Da published the "Study on the Vocal Music of Kunqu Opera" (Kunqu Changqiang Yanju, Wu, Jun-Da

\footnotetext{
${ }^{8}$ Published by Music Publishing House of Shanghai in 1982.

${ }^{9}$ Published by People's Music Publishing House in 1993.

${ }^{10}$ See the Institute of Chinese Opera: "A Compilation of the Percussion Music of Beijing Opera" (Jingju Dajiyue Huibian), People's Music Publishing House, 1958.
} 
1988). This book was highly praised among the Chinese scholars. Lian Po has published a theoretical book on composition of the music of Chinese operas titled "Composition of Chinese Operas" (Xiqu Zuoqu). ${ }^{11}$ It is focused on the music of Beijing opera and Kunqu opera.

Folk dance music is less complicated than any other music, due to the body actions involved in performance. For many dance genres, only percussion instruments are used as accompaniment. Some folk dance genres, of course, use melodic instruments. The music, originally as the accompaniment of dance, which involved melodic instruments, has always considered as pure ensemble music. Chinese scholars have paid little attention to this music except for collecting. For this reason we can find a large number of collections but little research. Two contributions we should mention here are "A Selected Collection of folk Dance Music" (Minjian Wudao Yinyue Xuan) by Zhao Kui-Ying ${ }^{12}$ and "Song and Dance and Song-Dance Music" (Gewu Yu Gewu Yinyue) by the Musical Institute of the Central conservatory of Music. ${ }^{13}$

Study on the Chinese narrative songs is more attractive abroad than in China, since Chinese musicologists are mainly trained as musicians and narrative songs involve fewer musical aspects than any other musical categories. However, several publications have been published. The books on the narrative songs we can find are "General Introduction to the Chinese Narrative Songs" (Quyi Yinyue Gailun) by Yu Lin-Qing ${ }^{14}$ and "Articles Collection on Chinese Narrative Songs" (Zhongguo Quyi Lunji) by Chinese Narrative Songs Press in 1984.

In recent years, research on religious music has become a popular subject. Not only collections and research works of the Chinese religious music have been done by various scholars, for example, Tian Qing has published a book titled "The Selected Chinese Buddhist Music" (Zhongguo Fojiao Yinyue Xuancui $) ;{ }^{15} \mathrm{Pu}$ Heng-Qiang has published his contribution on Chinese Taoist music "Taoism and Chinese Tradition Music" (Taojiao yu Zhongguo Chuntong Yinyue $){ }^{16}$ Lin Per-An has contributed two articles: "The Shuilu Ritual as Buddhist Oblation - The Ritual of Chinese Buddhist Chanting" (Conglin Duhua Guan Shuilu - Zhongguo Fojiao Fanbei Yigui Qiantan) ${ }^{17}$ and "Seeking the Origins of Buddhist Chant - The Ancestry of Buddhist Music" (Fanbei Kuiyuan - Foqu Bianzong), ${ }^{18}$ but also two ensemble groups: Beijing Zhihua Si Temple

\footnotetext{
${ }^{11}$ Published by Music Publishing House of Shanghai in 1989.

${ }^{12}$ Published by Spring Wind Literature and Arts Press in 1983, Shengyang, China.

${ }^{13}$ Mimeograph by the Musical Institute of the Central Conservatory of Music in 1961.

${ }^{14}$ Published by People's Music Publishing House in 1993.

${ }^{15}$ Published by Music Publishing House of Shanghai in 1993.

${ }^{16}$ Published by Wenjing Press (Taiwan) in 1993.

${ }^{17}$ Art of Music (Yinyue Yishu), No. 2, 1988: 28-32.

${ }^{18}$ Art of Music (Yinyue Yishu), No. 3, 1989: 18-21.
} 
Buddhist Ensemble and Suzhou Xuamiao Guan Temple Taoist Ensemble, have been re-established. Both groups had concert-tours to Europe. The commercial exploitation of religious music has also been made by the Chinese record companies. Shanghai Audio and Video company has published "The Vocal Liturgy of the Tianning Si Temple" (Tianning Si Changsong) in 1991, which contains a set of 3 audio-cassettes.

Except the individual research mentioned above, several composite contributions have also been published. Three of them to be mentioned here are "Introduction to Chinese Music" (Minzu Yinyue Gailun, Musical Institute 1991), "Compendium of Chinese National Music" (Zhongguo Minzu Yinyue Daxi, Xia Ye and Chen Ying-Shi 1989 ), and "Macro View of Chinese Music" (Zhongguo Minzu Yinyue Daguan). ${ }^{19}$ "Compendium of Chinese Music" contains four volumes: instrumental music, opera music, ancient music and narrative music. "Macro View of Chinese Music" covers all aspects of Chinese music, including history, different genres of both China's majority and minority music, religious music, as well as music of Taiwan.

There are thousands of national folk music instruments in China. These instruments present both historical reflection and present elements. Everywhere in China's large land, one can find different types of instruments and instrumental music. Such instruments and music show not only common features of China's musical culture in general but also a strong locality in particular. Consequently, study of Chinese instruments and music is always attractive to musical scholars.

Study on Chinese instruments and instrumental music can be illustrated from two points of view: study of instruments and study of instrumental music. The first point concerns more acoustic studies. In addition to a number of studies of each particular instrument, the following two phenomena are of special interest. The first is the innovations of Chinese musical instruments. Under the influence of Western orchestration, several China's large national orchestras have been established. They include the National Music Orchestra of Central Broadcast, the Central National Orchestra in Beijing, and the National Orchestra of Shanghai. Traditionally, the orchestras of ensembles for Chinese instrumental music were small. In most cases, they contained four to eight members. For the China's Westernised national orchestras, each of them may contain forty to seventy players. This type of orchestra is, too, divided into four instrumental groups: bowed-strings group, plucked-strings group, wind group and percussion group. These is a fact that the Chinese instruments have insufficient bass level sound available for a large orchestra. In order to avoid this insufficiency, starting in 1960s, Chinese musicians and music instruments makers have together starting tried to create new instruments. The bass-erhu, which was developed from erhu,

\footnotetext{
${ }^{19}$ Chief Editor are Qin Yong-Cheng and Wei Li. Published by Publishing House of Panyang, China in 1989.
} 
was one of earliest to appear. This instrument is similar to erhu but large. The techniques of playing remained the same as playing erhu. The bass-Ran can be seen as the second step. Ran (four-stringed plucked lute with a round sound box) is one of Chinese plucked instruments. First of all, this instrument was developed three different sizes, small, middle, and large. Secondly, it was further developed larger. Finally, there developed various types and they changed the way of playing from plucked to bowed as cello. To add the buttons on wind instruments can be seen as the third step. This innovation started from $d i$, later developed to guan (vertical double-reed pipe), suona (double-reed shawm) and sheng (mouth organ). Mouth organ, not only got added the buttons but also changed way of playing from pipes to keyboard as organ, although air coming from mouth of the player remains unchanged. There are also many innovations on several other instruments. For example, added modulation keys on zheng (plucked zither with tuning bridges) added more frets on pipa. The innovation of ways of fitting strings from manual to mechanical, and change of the string from traditional made of silk to the modern made of metal happened to almost every stringed instrument.

The division of study of Chinese instrumental music is something we are mainly concerned here. A great deal of this study has been done by Chinese scholars. This study covers the whole of area of instrumental music from a single type of instrument to general study and from one musical element, such as rhythm, to the whole scope of music. Some of the studies are very significant. Prof. Gao Hou-Yong (1981) published the first book on Chinese instrumental music. In this book, he studied different types of instrumental music popular in different areas, and provided general knowledge of Chinese instrumental music. Prof. Yuan Jing-Fang (1987) published her significant book after teaching several years Chinese instrumental music in the Central Conservatory in Beijing. In this book, Yuan focuses on the instrumental music of Han nationality. She has divided the music into two parts: solo and ensemble. In the part of solo, she studies several instruments which are quite commonly used as solo. These instruments are erhu, banhu, (two-stringed fiddle with coconut sound box) pipa, qin, zheng, di, sheng, and guan. Yuan studies both historical musical literature and modern development on these instruments. In the part of ensemble, Yuan has focused mainly on the most influential genres, such as Jiangnan Sizu (silk and bamboo ensemble of Southern Jiangsu province), Guangdong Yinyue (music of Guangdong), Xian Guyue (drum music of Xian), Hebei Cuige (wind songs of Hebei), Liaoning Gucui (drum and wind of Liaoning), Sunan Cuida (wind and percussion of Southern Jiangsu province), and others, she is not only concerned with the studies of historical development, of instruments, of orchestra but also of musical analysis. Specific studies on the musical structure of each type of ensemble music is given following each chapter. Prof. Ye Dong (1983) is mainly concerned with study of the structure of Chinese instrumental music. He classified structure of Chinese ensemble music into different types based on a large 
number of analyses. "The Universe of Music - A History, China Supplementary, volume 1: instruments" is one of the projects of UNESCO/IMC (International Music Council). Half of the volume is selected from historical pictures on Chinese instruments. The text for each instrument is scientific although short.

In addition to the research publications, a large a mount of collections have been published as well. Republication of qin's music is truly magnificent work. Under the support of the State, China started to republish the historical books of qin. Most of the volumes that have been republished are musical scores. Unlike other separated collections on qin music, this series of republications is photocopied without any Westernised transcriptions. Prof. Yang Yin-Liu published two volumes of collections on music in Jiangsu. These two collections are "Shifan Luogu", which is a genre of percussion music, and the "Music of Shifan $G u$ from Southern Jiangsu Province", which is a genre of ensemble music. The "Anthology of Chinese Folk Instrumental Music" is a magnificent work. This nationwide anthology is done by the Office of Instrumental Music Anthology and its branches in each province under the responsibility of the Committee of the Anthology of Chinese Traditional and Folk Music. This work still continues and several volumes have been published. (See "Introduction B. d.")

Besides the research and collecting on the music mentioned above, notation study is also one of the most important areas of study. Interesting topics include both the notations presently used in different areas and, especially, the notations found in caves or in ancient writings. Scholars are trying to decipher these marks and translate them into modern notation in order to reconstruct the authentic musical sound.

Scholars in Hong Kong and Taiwan have also presented contributions. In 1988, international conference on Chinese music was held in Hong Kong. The articles presented at the conference have been collected and published. ${ }^{20} \mathrm{Liu}$ Qing-Zhi, a researcher in Hong Kong, has published her book titled "National Music Research" (Minzu Yinyue Yanju) in 1989. ${ }^{21}$ The book contains Chinese instrumental music and music history. An English summary is included. Hsu Tsang-Houel, a scholar in Taiwan, has also written a large publication: "The Introduction to National Music" (Minzu Yinyuexue Daolun) covers various instrumental genres. ${ }^{22}$ His another contribution called "Ethnomusicological Essays I, II, III" (Minzu Yinyue Lunsu Gao) written in both Chinese and French languages. ${ }^{23}$

\footnotetext{
${ }^{20}$ This compilation was edited by the library of music department of Hong Kong Chinese University and the Research Society on National Music of Hong Kong, and published by Education Press of Shandong province, Chinese in 1990.

${ }^{21}$ Published by Shangwu Yinshu Press.

${ }^{22}$ Published by Yueyun Press (Taiwan) in 1993.

${ }^{23}$ Published by Yueyun Press (Taiwan) in 87,88 and 89.
} 


\section{b. Major musical journals}

(1) Musical journals published in mainland China

"Musical Research" (Yinyue Yanjiou), published quarterly by editorial office of the musical research of the People's Music Press. Academic articles on world wide music, whether on the musicology, ethnomusicology, musical philosophy, or musical education, are published in the journal.

"People's Music" (Rinmin Yinyue), published monthly by editorial office of the journal under the responsibility by the Chinese Musicians Association. Both academic articles and introductions on the music of world wide could be selected. The length of articles is limited.

"Chinese Music" (Zhongguo Yinyue), published quarterly by the Chinese Conservatory of Music in Beijing as the journal of the conservatory. Articles published in this journal are limited only on to the Chinese music. Articles are short and academic.

"Chinese Musical Education" (Zhongguo Yinyue Jiaoyu), published monthly by People's Music Press under the administration of the China State Education Committee. All articles published in the journal are concerned with musical education.

"Musical Composition" (Yieyue Cuangzu), published quarterly by the Chinese Musicians Association. Only musical compositions are published in the journal.

"Chinese Musicology" (Zhong guo Yinyue Xie), published quarterly by the Chinese Music Institute in Beijing. Only academic articles on the world wide music are published on the journal.

"The Journal of the Central Conservatory of Music" (Zhongyang Yinyue Xieyuan Xiebao), published quarterly by the Central Conservatory of Music in Beijing. Academic articles on folk music, Western art music history, music education and musical performance are published.

"Art of Music" (Yinyue Yisu), the journal of the Conservatory of Music of Shanghai (Shanghai Yinyue Xieyuan Xiebao), published quarterly by the Conservatory of Music in Shanghai. World wide music articles are published in the Journal.

"Academic Information on Music" (Yinyue Xiesu Xinxi), published quarterly by the Chinese Music Research Institute. Short articles on world music information are published.

There are also five other journals of the conservatories published quarterly: 
"The Yellow Bell" (Huang Zhong), the journal of the Conservatory of the city of Wuhan;

"Harmonica" (Jiao Xiang), the journal of the Conservatory of the city of Xian;

"Musical Research" (Yinyue Tansuo), the journal of the Conservatory of Sichun province;

"Music Academy and Musical Research" (Yinyue Xиesu Yu Yanju), the journal of the Conservatory of Tianjin.

"The New Sound of Music House" (Yuefu Xinsheng), the journal of the Conservatory of Shenyang.

(2) Musical Journals in Taiwan

"Music Research" (Yieyue Yangju), published yearly by the Music Institute of the Taiwan State Normal Arts College.

"China Musical Culture Education" (Zhonghua Yieyue Wenhua Jiaoyu Zazhi), published monthly by the Foundation of the China Musical Culture Education. Chief editor is Chen Gong-Xuong.

"Music Garden" (Yue Yuan), edited by editorial board of the journal under the Music Department of the Taiwan State Normal Arts College.

"The Tune of Purple Bamboo" (Zizu Diao), edited by the Music Department of the Home Economic School of the city of Tainan.

\section{c. Institutions of Chinese Music}

\section{Conservatories}

There are nine conservatories in mainland China: the Central Conservatory in Beijing, the Chinese Conservatory in Beijing, the Shanghai Conservatory, the Xian Conservatory, the Guangzhou Conservatory, the Tianjin Conservatory, the Shengyang Conservatory, the Sichuan Conservatory in Chendu, and the Wuhan Conservatory. All these conservatories have Chinese national music department, which is available to study Chinese music. Musicology as a separate department is only included in the Central Conservatory and the Shanghai Conservatory. These two departments give theoretical courses on Chinese music. Other conservatories also accept students, who have already finished a B.A. degree to study Chinese music for pursuing a master's degree.

Research Institutes

The Chinese Music Institute is China's sole music institute, which administratively belongs to the Chinese Academy of Arts. The Central Conservatory and the Shanghai Conservatory have their own music research institute. Additionally; 
many provinces and cities have either their own arts institutes, which are the succors of the music research, or local folk music organisations.

\section{Other Musical Institutes:}

Several institutes of Chinese opera and narrative arts exist in China. The Chinese Opera Academy is the only one which belongs to the academy of high educational. Northern Narrative Arts School in Tianjin is one of the best schools in China. In this school, the students learn narrative arts which are popular in northern China. In arts colleges and teacher's colleges as well as universities, there are many music departments for studying.

\section{d. Government administration and influence on Culture After 1949}

All musical units, including academic units, are administrated by the state. The social and educational functions of music are emphasised, with the focus on the transmission of ideology. Policies relating to musical activities and contents reflect the Communist party's points of view.

The government administrative units can be divided into several levels. At the top, there is the Council of State; below this, there is the state's Ministry of Culture; following, there are Cultural Bureau in the cities and provinces, and Cultural Offices in the counties or districts.

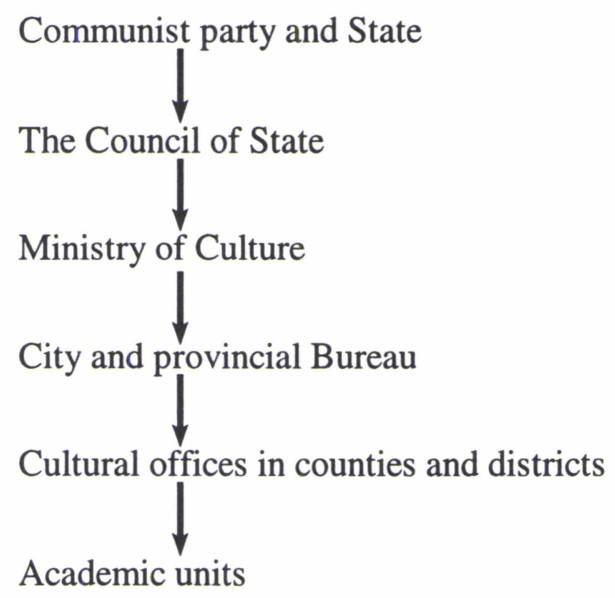

Illustration 1. The Government Mechanism on the Culture.

There are many administrative units, in charged of different areas of cultural work. Branches of the Party have also been established in the academic units; for 
example, the Chairman of the Musical Conservatory Communist Party branch has very powerful influence on administrative questions.

The units and branches of the government have a significant influence on the cultural activities. First of all, strategies and policies are formulated by the government and the Party.

Secondly, the government pays for all expenses incurred, including salaries. Due to the large scale of expenses involved in organising any musical projects, it is evident that the success or failure of the project depends solely on government's support.

For example, there is an ongoing national project (started from 1979) which is called "Anthology of Chinese Folk Music" (Zhongguo Yinyue Jicheng). This is an immense big project, both in terms of manpower and resources required; it covers the whole of mainland China, namely 22 Provinces, 3 central controlled cities and five autonomous regions. The anthology is divided into six different categories in accordance with Chinese folk music classification, i.e. instruments, opera, song, narrative songs, folk dance and qin music. For each of categories, a series of volumes is to be published for each province or city, containing musical transcriptions and instructions. The work involves the process of reading, recording, selecting, writing and finally condensing the results for publication. The whole project is organised and overseen by the "Committee of the Anthology of Chinese Traditional and Folk Music" under the responsibility of the Culture Ministry, the Committee of Affairs of Nationalities, and the Chinese Musicians Association. Six deputy offices have been established according to the six categories. Each of these deputy offices has a branch in each of provinces, cities and regions. A branch has its correspondent in each of counties. Several volumes which have been published are: "Anthology of Folk Songs", Hubei volume (1988) and Shanxi volume (1990); "Anthology of Instrumental Music", Shaanxi volume (1992); "Anthology of Folk Dance", Jiangsu volume (1989). Such a project requires heavy financial support, and illustrates the necessity of subsidisation from the Chinese government.

Thirdly, the Chinese Communist Party consistently emphasises Marxism, Leninism and Maoism as principles underlying academic scholarship. In many ways, the government and the Party participate in project not only through the personnel appointed as leaders of study groups, but also within the thinking.

\section{e. Ambiguous concepts of the "insider" and "outsider" in Chinese ethnomusicology}

In ethnomusicology, the "insider" and "outsider" are two important concepts, relating to the researchers and the people whose music is being researched. For example, Western scholars are considered as "outsiders" and their informants are termed "insiders", whenever they are studying non-western music. For example, 
Stephen Blum states that "We cannot restrict ethnomusicology, in principle, to studies of non-western societies, conducted by western scholars, for use within the West." ${ }^{24}$ Similar statement has been given by many Western ethnomusicologists. Nettl, for example, says that ethnomusicologists are "members of affluent societies who study the music of the poor." (Nettl 1983: 260) Mantle Hood also depicts that "A study of music outside the European art tradition but researched and talked about in the vocabulary of western parlance compounds the problem of oral variants", "Speaking and writing about music are cultivation of the Western world". ${ }^{25}$ I would like to argue that this definition, which may have been correct before the non-western scholars emerged, has now become inequitable and can not be used in the present context, simply because the field of ethnomusicology and scope of the ethnomusicologists have become increasingly complex.

In earlier ethnomusicological history, ethnomusicological research was mainly conducted by the Western scholars who study non-western music. Such as the famous publication in 1767 by Jean-Jacques Rousseau, the field was more concerned with the music of non-western or non-literate cultures. Rousseau gives samples of folk, Chinese and American Indian music. (Nettl, 1964: 13) Another example is Corl's study concerning Indian songs, which is regarded by some scholars as the first real ethnomusicological publication, and won praises from a respected critic, Bruno Nettl, who describes Corl Stumpf's work as a milestone in ethnomusicology (Nettl 1964: 70). There are two significant developments ethnomusicologists had made after 1950s are that the music and researchers of the ethnomusicology become much wider than what it has been before. Nettl (1964: 14) pointed out that the ethnomusicologist deals mainly with three kinds of music. Main characteristic of ethnomusicology and its history perhaps is the music of non literate societies. The other two kinds of music that ethnomusicologists should focus in their study are the Asian and the North African high cultures and folk music, which may be defined as the music in oral tradition found in those areas which are dominated by high cultures. (Nettl 1964: 5-7) John Rahn views that the field of ethnomusicology should include music from many cultures, include Western art music. ${ }^{26}$ On the other hand, a large number of the ethnomusicologists have emerged from the nations out of Western countries. Yang Yin-Liu, for example, what he has done is magnificent. His knowledge and the number of his publications on Chinese music, I assume, has not been compared until now by any one both from inside China and abroad who study Chinese music. Nettl also noticed the scholars who came from Non-

\footnotetext{
${ }^{24}$ Stephen Blum and Philip Bohlman and Daniel Neuman: "Ethnomusiclolgy and Modern Music History", University of Illinois Press, 1991: 17.

${ }^{25}$ Mantle Hood: "The Ethnomusicologist", The Kent State University Press, 1982: 199, 219.

${ }^{26}$ John Rahn: "Ethnomusicological approach to Western Art Music: A Native Reflection", The world of Music, vol.xxix No. 1, 1987: 9-15.
} 
western countries, saying

one of the major events in ethnomusicology since 1950 is the development of scholars in non-western nations who study, if not the music of their personal tradition, then that of their nation or region (1983: 263).

Accepting the description of Japanese scholars such as Shigeo Kishibe, of Japanese music, or the studies of West African tribal music by African scholars, such as J.H. Kwabena Nketia, has become perfectly acceptable to Western ethnomusicologists. Indeed, Nketia seems to believe that the outsider i.e. westerner, does not have as good a chance of bringing out the essentials of a musical culture as a trained, native, insider (1964: 70).

One can argue that "ethnic" applies not only to people who belong to the nonliterate cultures, but also to those who belong to the high cultures, including the Western civilizations. If we call the scholars such Shigeo Kishibe or J.H. Kwabena Nkertia as insiders or outsiders, then what about the Western scholars who study Western folk or art music? Are they "insiders" or "outsiders?" Or, what about non-western scholars who study Western folk music?

I believe that there are differences between the thinking of scholars such as Nketia and that of Western scholars. This is to be expected, and arises out of differences in roots, for example their cultural background, society experiences and languages. Their roots affect them so much that they exhibit vast differences of opinions, and their emotional responses to the same set of events can be very different, even where they have a similar level of education. These are the sort of problems that are encountered when one tries to determine whether an investigator should be termed as an "insider" or "outsider"?

In China, ethnomusicology is a relatively new subject. The first individuals who have studied ethnomusicology, such as Wang Guang-Qi, appeared around the decade of 1920s, but ethnomusicology as an academic subject, I would argue, was only established around 1950 . Two of the most important pieces of evidence supporting this point relate to the foundation of the Institute of Chinese Music Research in 1953, headed by Yang Yin-Liu, and the Musicology Department which was established in 1951. Both the Institute of Chinese Music Research and the Musicology Department are under the hierarchy of Central Conservatory of Music in Beijing. The name given to the field of Chinese music research was "min zu yin yue xue" (musicology of national music). Significant differences ethnomusicological research in China after 1950 from what had been before are: firstly, researchers became a group rather than individuals; secondly, researchers root their stems in China, rather abroad (Wang, Guang-Qi, for example, he studied musicology in Germany); thirdly, the consciousness of ethnomusicology (minzu yinyue xue) has been established.

From the establishment of these institutions, students who wanted to study ethnomusicology had the chance of formal education. During the past 40 years, 
ethnomusicology has been developing rapidly. Courses of ethnomusicology have been set up at several musicology departments, including the Central Conservatory and Chinese Conservatory in Beijing, the Shanghai Conservatory, and the Institute of Chinese Music Research in Beijing. Courses in Chinese music are also usually available at the other Conservatories and colleges of Arts. Many ethnomusicologists from the United States or European countries have also given extensive lectures and courses on the subject. Some Chinese ethnomusicologists have even ventured abroad either to work or to further their study.

Cultural units in China can be divided into different levels, ranging from the central ones under the responsibility of the Ministry, such as the Central Conservatory of Music, to the local units at province and county level. Chinese ethnomusicologists thus represent an enormous body of resources and talent. Three levels are clearly evident among Chinese ethnomusicologists:

(1). The first level are those who have been formally educated in ethnomusicology and Western musical theory. They can be found working in the big cities, due to higher incomes and the availability of infrastructures and facilities to further their interests and study.

(2). The second level are those who educated in the values of the Chinese traditions, but are limited in their knowledge of Western musical theory. Usually they can be found working in the capitals of the provinces, and they are said to have rich musical resources and materials.

(3). The third level are those without formal education. They have little knowledge of the theory of music and are located mainly in the countryside. Their musical knowledge has been acquired from by experienced musicians like themselves, and the materials used have been passed down through generations.

In the light of these points, it would be a mistake to define all Chinese scholar as "insider". The emphasis on demography, race or religion is evidently erroneous, since Chinese ethnomusicologists who belong to the third level would regard Chinese scholars belonging to the first level as "outsiders".

Scholars who belong to the first level apply Western theory and method in their analysis and study of Chinese music. They are different, however, from Western scholars, since they analyse the subject in terms of Chinese thinking and Chinese feeling. They can be considered to form a kind of bridge between the Western and Chinese approach. The scholars belonging to the second level, however, seem to prefer an approach along the line between the Chinese folk and scholarly tradition.

It is thus clear that there are difficulties in attempting to define, with respect to Chinese ethnomusicologists, the "insider" and the "outsider". One approach would be to consider that there is the existence of various levels for both "insiders" and "outsiders". Depending on the level, a scholar might be an "outsiders" compared against one who belongs to a lower level ("insider"), or vice-versa when compared against a higher level. 


\section{Chinese Music Research in the West}

Publications on Chinese music are few in comparison with the boundary of the Chinese musical culture. (Kouwenhoven, 1990, a.) But this does not to mean that the Chinese study of music were without merits. Both Chinese and Western scholars have already conductive fruitful research into Chinese music.

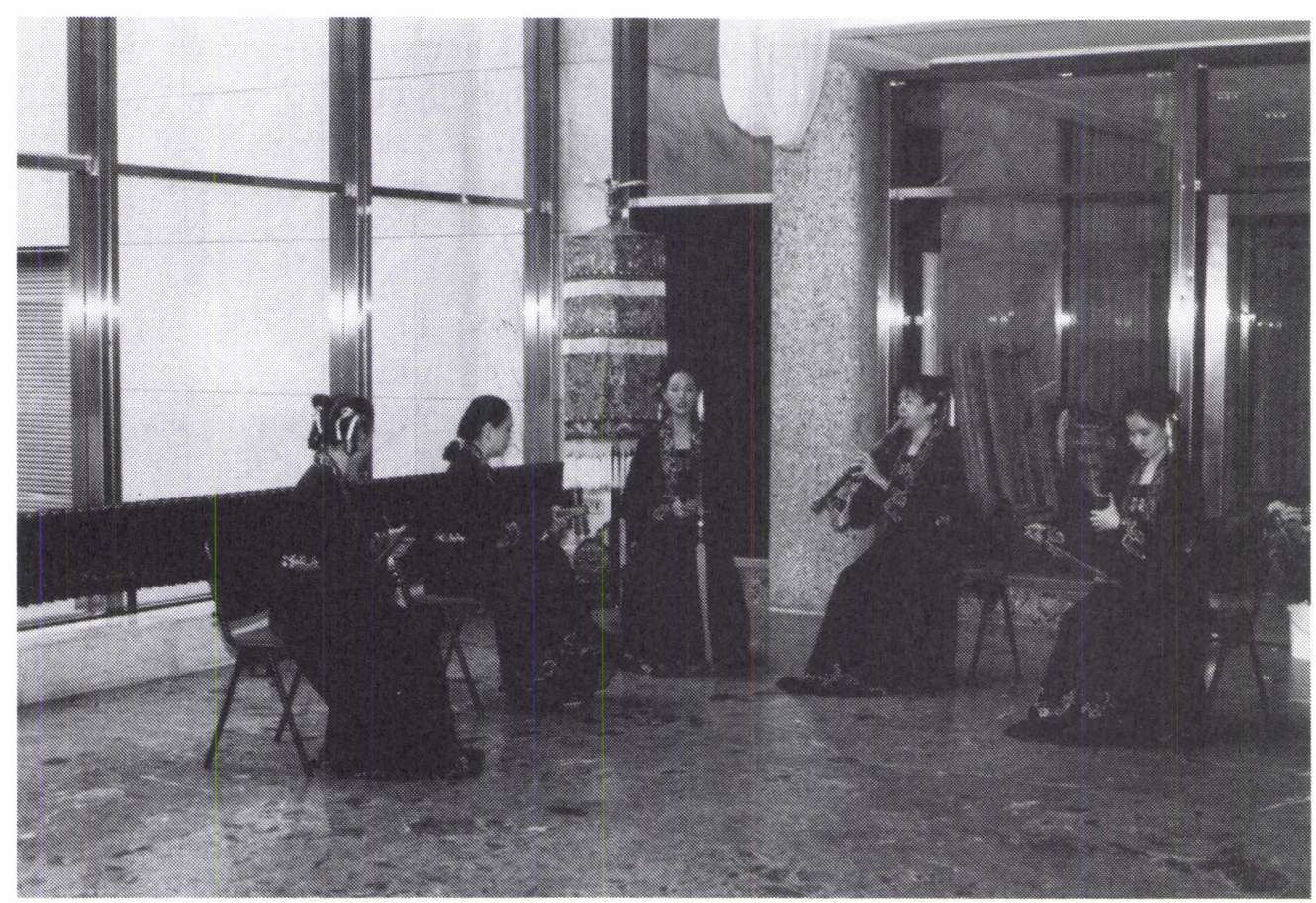

Picture 4. Fujian Nanyin (Southern sound of Fujian province) ensemble from Taiwan giving a performance during the International Conference on Eastern Asian Music, held in Rotterdam, Holland in 1995. Photograph by Boyu Zhang.

\section{a. Defining the Chinese Musical Research in the West}

It is really necessary, at the first place, to define the scope of the Chinese musical research in the West. Is the research by Western scholars really Chinese music research in the West? Or are publications in Western languages really Chinese music research in the West? If this is the case, what about publications written by Western scholars but published in China? Who is a Western scholar? What principles could be used to define him? Has he to be white colour? What about overseas Chinese? There are many Chinese who live in a Western country and 
teach Chinese music. Are they Chinese scholars or Western scholars? To discuss such questions is out of this author's interest. The scope of the Chinese music research in the West here is simply defined as any research work done by a scholar who lives outside of China and any publication published outside of China. Thus, the scholar can be a Chinese but not live in China, or publication can be in Chinese but not published in China.

\section{b. Popularity of the Chinese musical research in the West}

With its vast musical resources in China, the Chinese music research is an attractive topic in the West. In many universities, both in Europe and Northern America, are offered courses on Chinese music. The scholars who study Chinese music in the West belong to two different groups: the Westerners and the overseas Chinese. Both groups identity themselves as not only musicologists but also as sinologists.

The scope of the Chinese music research in the West is very wide. In general, there are two area of interest for Western scholars: historical resources and living music traditions. On the first topic, some of important publications are: Rulan Chao Pian: "Sung Dynasty Musical Sources and Their Interpretation" (1967); ${ }^{27}$ Laurence Picken: "Tang Music and Musical Instruments" (1969); ${ }^{28}$ "Music from the Tang Court" (1987), ${ }^{29}$ Fritz Kuttner: "A Musicological Interpretation of the Twelve Lus in China's Traditional Tone System" (1965); ${ }^{30}$ "Prince Chu TsaiYu's Life and Works" (1975a); ${ }^{31}$ "The 749-Temperament of Huai Nan Tzu" $(1975 b) ;^{32}$ Kenneth Girdwood Robinson: "A Critical Study of Chu Tsai-yu's Contribution to the Theory of Equal Temperament in Chinese Music" (1980); ${ }^{33}$ Anne M. Birrell: "Mythmaking and Yueh-Fu: Popular Songs and Ballads of Early Imperial China" (1989); ${ }^{34}$ Colin Mackerras: "The Rise of the Peking Opera, 1770-1870 - Social Aspects of the Theatre in Manchu China" (1972); ${ }^{35} \mathrm{Joseph}$ Lam and Sui Ching: "Creativity within Bounds: State Sacrificial Songs from the Ming dynasty" (1988), ${ }^{36}$ Keith L. Pratt: "The Evidence for Music in the Shang

\footnotetext{
${ }^{27}$ Harvard University Press, 1967.

${ }^{28}$ Toung Pao, Lerden 55, nos. 113: 74-122, Holland.

${ }^{29}$ Cambridge University Press, 1990.

${ }^{30}$ Ethnomusicology 9 (January, 1965): 22-38.

${ }^{31}$ Ethnomusicology 19 (May, 1975): 163-206.

${ }^{32}$ Asian Music 4,1975, nos. 1 and 2: 88-105.

${ }^{33}$ Commentary by Erich F.W. Altwein and preface by Joseph Needham. Sinologicacoloniensia 9 (Wiesbaden: Steiner, 1980) x.

${ }^{34}$ Journal of the American Oriental Society CIX / 2 (Apr. June 1989): 223-35.

${ }^{35}$ Clarendon Press, 1972, Oxford.

${ }^{36} \mathrm{PhD}$ diss., Musicology: Harvard University Press, 1988.
} 
Dynasty: A Reappraisal" (1986); ${ }^{37}$ Keneth J. Dewoskin: "Echoes of Deep Antiquity: Chinese Music Archaeology" (1990); ${ }^{38}$ Lothar Von Falkenhausen: "Suspended Music: Chime-Bells in the Culture of Bronze Age China" (1993). ${ }^{39}$

Due to difficulties in reading old Chinese literature, majority of scholar focus on the Chinese living music traditions. Walter Kaufman, edited "Musical References in the Chinese Classics", (1976) which is useful for finding information. In regard to musical genres, the Chinese music research in the West can be seen from the following aspects.

(1) On the Chinese songs: Sue Mary Clare Tuohy: "Imagining the Chinese Tradition: The Case of Huaèr Songs, Festivals and Scholarship" (1988) ${ }^{40}$ Han Kuo-Huang: "Folk Songs of the Han Chinese: Characteristics and Classifications" (1989); $;^{41}$

(2) On the Chinese opera music: Elizabeth Wichmann: "Listening to Theatre - the Aural Dimension of Beijing Opera" (1988); ${ }^{42}$ Bell Yung: "Cantonese Opera: Performance as Creative Process" (1989); ${ }^{43}$ Colin Mackerras: "The Chinese Theatre in Modern Times: From 1840 to the Present Day" (1975); ${ }^{44}$ John D. Mitchell, (compiler) "The Red Pear Garden: Three Great Dramas of Revolutionary China" (1973); ${ }^{45}$ Daniel Lee Ferguson: "A study of Cantonese Opera: Musical Source Materials, Historical Development, Contemporary Social Organization, and Adaptive Strategies" (1988); ${ }^{46}$ Jinperi Huang: "Xipi and Erhuang of Beijing and Guangdong Operas" (1989) $;^{47}$ Chan Sau-Yan: "Improvisation in Cantonese Operatic Music" (1986); ${ }^{48}$ Lindy Li Mark: The role of Avocational Performers in the Preservation of Kunqu" (1990), ${ }^{49}$

(3) On the narrative music: Tsao Pen-Yeh: "The music of Su-Chou-Tàn$T z^{\prime} u$ : Elements of the Chinese Southern Singing-Narrative" (1988), ${ }^{50}$ "Training of Tan Tzu Performers: Processes of Oral Transmission in the Perpetuation of

\footnotetext{
${ }^{37}$ Bulletin of the British Association for Chinese Studies (1986): 22-50.

${ }^{38}$ Asian art III/2 (Spring 1990).

${ }^{39}$ University of California Press, 1993.

${ }^{40} \mathrm{PhD}$. diss., Music: Indiana University Press, 1988.

${ }^{41}$ Asian Music XX / 2 (spring-summer 1989) 107-28.

${ }^{42}$ Honolulu: University of Hawaii, 1989.

${ }^{43}$ Cambridge University Press, 1989.

${ }^{44}$ Amherst: University of Massachusetts Press, 1975.

${ }^{45}$ Boston: D.R. Dogine, 1973.

${ }^{46} \mathrm{PhD}$. diss., Ethnomusicology: University of Washington, 1988.

${ }^{47}$ Asian Music XX / 2 (Spring-summer 1989), 152-95.

${ }^{48} \mathrm{PhD}$. diss., Music: University of Pittsburgh, 1986.

${ }^{49}$ Chinoperl paper XV (1990).

${ }^{50}$ Hong Kong: Chinese University, 1988.
} 
the Su-chou Singing-Narrative"; "The Oral and the Literate in Music" (1986); ${ }^{51}$ "Structural Elements in the Music of Chinese Storytelling" (1989).52 David Moser: "Reflexivity in the Humour of Xiang-Sheng" (1990) ${ }^{53}$ Kate Stevens: "The Slopes of Changban: A Beijing Drumsong in the Liu Style" (1990) $;^{54}$ Rulan Chao Pian: "Text and Musical Transcription of a Kaipian: Birthday wishes from the Eight Immortals" (1986), ${ }^{55}$ Zhang Cui-Fang: "My Life as a Drum Singer: The Autobiography of Jang Tsueyfang" (1984-85); ${ }^{.56}$ Wun Dou and Bell Yung: "Popular Narratives in the Pleasure Houses of the South"(1982). ${ }^{57}$

(4) On the instrumental music: Stephen Jones: "Chinese Folk Traditions" (1995); Liang David Mingyue: "Performance Practice as a Recreative Process in Chinese Zheng Zither Music" (1985); ${ }^{.5}$ "The Art of Yin-Jou Techniques for the Seven-Stringed Zither" (1980); ${ }^{.9}$ Nora Yeh: "Nanguan Music Repertoire: Categories, Notation, and Performance Practice" (1988), ${ }^{60}$ Alan R. Thrasher: "Structural Continuity in Chinese Sizhu: The Baban Model" (1989); "HakkaChaozhou Instrumental Repertoire: An Analytic Perspective of Traditional Creativity" (1988); ${ }^{62}$ John Edmund Myers: "Nanbei Erpai Miben Pipapu Zhenquan: A Critical Study of A Nineteenth-Century Handbook for the Chinese Pipa Lute" (1987), ${ }^{63}$ John Lawrence Witzleben: "Silk and Bamboo: Jiangnan Sihu Instrumental Ensemble Music in Shanghai (1987); ${ }^{64}$ "The Jiangnan Sizhu Instrumental Ensemble Tradition"; 65 John Myers: "The ways of Pipa: Structure and Imagery in Chinese Lute Music" (1992); ${ }^{66}$ Joseph Lam: "Analyses and Interpretations of Chinese Seven-string Zither Music: The Case of the Lament of Empress Chen" (1993) ${ }^{67}$ Jonathan Stock: "Three Erhu Pieces by Abing: An analysis of Improvisational Processes in Chinese Traditional Instrumental Music"

\footnotetext{
${ }^{51}$ Tokyo: Academia, 1986: 221-30.

${ }^{52}$ Asian Music XX / 2 (Spring-summer 1989) 129-51.

${ }^{53}$ Chinoperl paper XV (1990) 45-68.

${ }^{54}$ Chinoperl papers XV (1990).

${ }^{55}$ Chinoperl papers XIV (1988) 58-73.

${ }^{56}$ Chinoperl papers XIII (1984-85) 7-106.

${ }^{57}$ Chinoperl papers XI (1982).

${ }^{58}$ The world of music, 1985 (1): 48-67.

${ }^{59}$ PhD. diss. UCLA, 1973. Ann Arbor: University Micro-films, 1980. Xii 321.

${ }^{60} \mathrm{PhD}$. diss. University of California, Los Angeles, 1985: 481.

${ }^{61}$ Asian Music XX / 2 (Spring-summer 1989) 67-106.

${ }^{62}$ Asian Music XIX / 2 (Spring-summer 1988).

${ }^{63} \mathrm{PhD}$. diss. Music: University of Maryland, 1987: 874.

${ }^{64} \mathrm{PhD}$. diss., music: University of Pittsburgh, 1987: 245.

${ }^{65}$ Kent State University Press, 1995.

${ }^{66}$ Kent State University Press, 1992.

${ }^{67}$ Ethnomusicology 37 (3), 1993: 353-85.
} 


\section{(1993-94). ${ }^{68}$}

There are also many books and articles concerned not only with one aspect, but rather, presenting introductory. Liang David Mingyue published his "Music of the Billion: An Introduction to Chinese Musical Culture" (1980); Lui TsunYuen: "Introduction to the Traditional Music of China" (1978); Alan Thrasher: "The Role of Music in Chinese Culture" (1985); Tran Van Khe: "Chinese Music and Musical Traditions of Eastern Asia" (1985); Isabel K. F. Wong: "Music and Religion in China, Korea, and Tibet" (1987); ${ }^{69}$ Bell Yung: "Review of Recording: Chinese Music" (1987); ${ }^{70}$ Alan Thrasher: "The Role of Music in Chinese Culture" (1985), ${ }^{71}$ Laurence Pichen: "The Music of Far Eastern Asia, 1: China" (1957) $;{ }^{72}$ Walter Kaufmann has published a study book on the notation systems used by the Asian countries: "Musical Notations of the Orient. Notational System of Continental East, South, and Central Asia" (1967); Tran Van Khe has his article on Chinese religious music: "Buddhist Music in Eastern Asia" (1984). ${ }^{73}$ Helen Rees has her dissertation on the Chinese minority music: "A Musical Chameleon: A Chinese Repertoire in Naxi Territory" (1994). ${ }^{74}$

There are, in the West, several important research organisations on Chinese music. The Chinese Musical Research Foundation is based at Leiden University in Netherlands, and it associates many scholars around Europe as well as America and Asia. Its journal called "Chime" (Chinese Music Europe) is published in two issues a year (Spring and Autumn). The Chinese Music Society of North America is located in the United States. Its journal called "Chinese Music" (first published in 1978 as "Chinese Music General Newsletter) published quarterly. Association for Chinese Music Research (ACMR) resides at the University of Pittsburgh in the United States. Its publication called "ACMR Reports" also published regularly. Cornell University, East Asia Program is also editing a journal called "Chinoperl", which is published one a year. Society for Asian Music has also its office at Cornell University. Its publication called "Asian Music", which is published twice a year, is considered as one of important journals on the Chinese musical research in the West. Of course, one can find many articles on Chinese music in the journals or magazines such as The World of Music, Ethnomusicology, and Asian Music.

In many universities outside China, course on Chinese music have been

\footnotetext{
${ }^{68}$ Asian Music, vol. XXV, 1-2 (1993-4): 145-76.

${ }^{69}$ The encyclopaedia of religion, New York: Macmillan, 1987, 195-203.

${ }^{70}$ Yearbook for traditional music XIX (1987): 159-60.

${ }^{71}$ The world of music 1985 (1): 3-18.

72 In the New Oxford History of Music, 1: Ancient and Oriental Music, edited by Egon Wellesz, Oxford University Press, 1957: 83-134, London.

${ }^{73}$ The world of music 84 (3): 22-32.

${ }^{74} \mathrm{PhD}$ diss., University of Pittsburgh, 1994.
} 
given. For example, in the United States, the Chinese music can be studied at the Harvard University, Indiana University, Northern Illinois University, Skidmore College, Wesleyan University, California University, Missouri University, Pittsburgh University, Kent State University, South Florida University, in Europe, Leiden University in Holland, School of Asian and African Studies in England, Essen University in Germany.

Among the topics focused by Western scholars, two seem to be more attractive. One is living traditions and other musical politics. On the first topic, publications are more introductory regarding music traditions existing in China. Such books or articles can be found not only in English but also in other languages such as German, French, as well as in Finnish. The second topic seems to be more interesting to the Western readers, because it is something about modern Chinese music history. In general understanding, there is a lot of criticisms about the situation of music in China, especially during the time of Cultural Revolution (1966-1978).

One can not deny the contributions Western scholars have made on Chinese music research, although opinions differ about it. As many Chinese studies, the centre of the research is not in China but in the West. The Sinology has been developed in the West in hundreds of years. The famous British Sinologist Joseph Needham's research and publications have been regarded the best by both Western and Chinese scholars. Similarly, the publication on the theory of modes of the Chinese ancient music done by Japanese scholar Hayashi Kenzo was translated into Chinese by the famous Chinese historian and archaeologist Guo Mo-Ruo. ${ }^{75}$ The theories presented in the book are widely accepted by Chinese scholars. In the same way, Chinese scholars have realised the value of Chinese music from the work by Western scholars.

On the other hand, I should say that most of researches on the Chinese music done by Western scholars are more introductory, although some of them are quite comprehensive. Because of language as well as other kinds of cultural handicaps, Western scholars usually look at things in a certain perspective. They understand music much based on music itself and social behaviour related to the music, but difficult to obtain the inside feeling of the sound of music and the documents which are related to the music not only historically but also culturally. They may more interested in the way of playing of music, musician's manners during the playing, environment of the music playing, and so on, on the other hand, however, these are not topics treated by the Chinese scholars, due to the knowledge of such topics is already known by any reader. Secondly, resources used by Western scholars are very much based on the researches done by Chinese scholars. This is because of the limits on finance and time, a Western

\footnotetext{
${ }^{75}$ Guo Mo-Ruo: "Study of the modes of the banquet music in Sui and Tang dynasties", Shangwu Publisher Press, 1936.
} 
scholar can not go to or live in China for a too long period. A Chinese scholar, needless to say, will spend his whole life in China. The musical spirit will be as part of his life. Thirdly, there are some mistakes on the general knowledge of Chinese music can be found in the research works done by Western scholars. Because language understanding might be difficult and information a Western scholar get may be incorrect, mistakes sometimes happen. The use of the term of "Yue Zhong", for example, has been misunderstood as musical genre study as reconsideration of the classification of five categories (folk songs, instrumental music, narrative songs, operatic music, and folk dance music. See Steven Jones 1995: 4-5). Yue means music and Zhong means genres. Yue Zhong used as a term contains various meanings. For Prof. Yuan Jing-Fang, it is limited to be used only for instrumental ensemble music comparable to the Ge Zhong (folk song genres), $Q u$ Zhong (operatic genres), ${ }^{76}$ but for Prof. Dong Wei-Song it means not only the instrumental genres but also genres of narrative songs, operas, folk dance, as well as part of folk songs. ${ }^{77}$ Yuan has also established a research theory Yuezhong Xue (Theory of Yuezhong), which is a method of analysis used to find out the oldest pattern of a piece of ensemble music which has been found to play in different areas.

\section{c. Differences in focus between Western and Chinese musicologists}

There are significant differences between the Chinese and Western ethnomusicologists in focus of the research. Western ethnomusicologists are more interested in the study of a musical genre, concentrating both on the structure and the cultural significance of the music. They tend to study the music with emphasis not only on the music itself, following the earlier German school, but also on its relation to social life and human behaviour, as propounded by the earlier American school. ${ }^{78}$ The questions asked by Western ethnomusicologists can be exemplified as follows: What kind of people are the performers? What kind of audiences do they attract? For what occasions do they play? Where does their repertory stem from? Is there a hierarchy in the ensemble playing? How does one learn to play? Is any of the music preserved in written notation or is it a purely oral genre? Are we talking about dead music or is it still performed today? Are there any the genre groups or performers left in the areas where the genre is popular? More recently, both in European countries and in the United

\footnotetext{
${ }^{76}$ Yuan Jing-Fang: "The Theory of Yuezhong", The Journal of the Central conservatory of Music, No. 1, 1992.

${ }^{77}$ Dong Wei-Song: "Chinese Ethnomusicology and the Problem of Yue Zhong and the Method of Classification", published in Essays Collection about National Music, China Arts and Literature Press, 1994: 30-47.

${ }^{78}$ Alan Merriam: "The Anthropology of Music", Northwestern University Press, 1964: 3-6.
} 
States of America, these two schools have become fused.

On the other hand, Chinese ethnomusicologists, being more knowledgeable about local historical events and more familiar with the musical instruments of their own country, are more interested in the deeper aspect of the music as it interrelates with their own roots. Questions frequently asked by Chinese ethnomusicologists concentrate on the instrument itself and techniques used in producing the music, roles played by the various musical instrument and the order of importance, the historical events leading to its creation, and structural and musical contents in terms of scale, tonality, melody and rhythm. ${ }^{79}$

${ }^{79}$ The following example will illustrate this problem.

In the beginning of 1984, when I was a student at the musicology department of the Central conservatory of music, a few of us were sent to Liangshan area of Sichuan province to do field work as part of our training. This area is a minority area, inhabited by the $Y i$ clan. The location is in the mountains and the people were living in a poor economic situation. We stayed in a small inn at the county called Ganluo. Each day, we were taken on a tour of the countryside by one of the local cultural officer of the county.

One day, we were informed of a funeral in a village near the place we were staying. The funeral was scheduled to take place the next day. This was a good opportunity to understand further the music and culture of the clan. The following day, we walked for many hours, and as we approached the village, we saw that many people were converging from different directions. Coming along our direction, there was a group of more than a hundred people walking in a straight line. In front of the line, there was one player playing a wind instrument called Mapu (House Steps). The other people were bringing a cow.

When we arrived at the village entrance, fire crabs and fireworks were set off by the villagers before the visitors were allowed to enter the village. The dead body was laid on a bed without mattress, covered by a white cloth. Outside the room, there was a very big yard and there were many people standing around the yard. Soon after we arrived, some of the people tried to kill the cow. I saw a man who used his axe to beat the cow's head, causing it to drop to the ground. Another man used a knife to cut cow's neck, until only nape part connected the head and body. Blood spurted out from the neck.

By the time, I assumed the cow was dead, but to my horror, it opened its eyes and tried to stand up again. Then the man with the axe beat the cow's head again and again until the animal was definitely dead. Following that, a big pot filled with water was placed in the middle of the yard, and a fire was lit under it. The cow, which had been cut into pieces, was then put them into the pot.

After twenty minutes, the meat was taken out. Some cornflower was mixed with hot water in a big pan. A special bamboo spoon, called "Ma Shi Zi" in the Yi clan's language, was used for eating the meat, which was real tough. According to the $Y i$ people's tradition, salt should not be used in food for funeral; only chilli may be added, whereas in food for a wedding, salt and chilli can be used to together.

During the two weeks of field work, we were warmly invited to visit some of the families and villages. I remember a particular night in one of the villages. The leader of the village used a means of broadcasting to call villagers who were interested to sing to us to visit us at the place we were staying. Surprisingly, more than hundred people came to us to sing and to play music for our pleasure, without asking for money. Throughout our stay, they provided us with very good food.

How is one to understand such people? How can we understand such music, and analysis them? At that time, we really didn't know. We mainly focused on the instruments they played and 
There are three reasons for these differences between Chinese and Western ethnomusicologists.

Firstly, the gap is generated by the character of the music itself. Unlike music from primitive societies, Chinese traditional music is highly organised and was developed during the evolution of historical processes. Furthermore, the Chinese consider music as aesthetic enjoyment rather than a social event. Whilst it is close to the people's life, it is not as a must. For example, the Shifan Luogu, a type of percussion ensemble locally popular in southeast China, may be played during a ceremony, but such music is not critical nor is it essential for the completion of the ceremony procession.

Secondly, most Chinese ethnomusicologists are musicians as well. Music itself is highly emphasised in their work. To be a musicologist, the Beijing Central Conservatory of Music requires that one must first be regarded as a musician. Furthermore, the musicology department is located in the Conservatory, and not at the university, and the students' curriculum learns heavily on practical music, with little emphasis on humanity aspect of their education.

Thirdly, China has been isolated for a rather long time. Foreign languages have not been emphasised, as could be exemplified from the scholars who study Chinese music. Information from outside world has been severely limited. Music as a formal subject was not encouraged, even though the concept was quite popular in China.

The differences between the Westerners and Chinese could be narrowed by affording Westerners more materials concerning Chinese music. The more that one learns of the material, the closer he or she would be in understanding Chinese music. As for Chinese scholars, exposure to the outside world would eventually make them view their study from a different perspective. Unfortunately, the differences is still present significantly wide.

music they performed themselves. We measured how big each instrument was, and the distance between the holes. We noted what methods were used when a instrument was played, and what kind of musical structure each song used. I clearly remember visiting one young lady with two of my classmates to ask her to sing. She sang a lot but we still ask for more. She said she wanted to go outside, to sing some love songs to us but it is not allowed to sing such songs in the presence of parents. We went to outside, and she stood one of hillside to sing. Suddenly she stopped, and laughing, hid her face in her hands. When we asked why, the officer who was guiding us explained she was shying because of the content of the song. We said "don't be shy, we don't understand the content, we just want to listen to the music." That time, the concept of the context of music was only limited on the melody, rhythm, and a like. The content of the song was treated to be out of our perspective. But the context of music needs be much wider in Western thinking as suggested by Marcia Herndon and Norma Mclead that context comprises different several aspects, for instance, the physical, social, and linguistic context, the occasion as context, and son. (See Music as Culture, Norwood Edition, 1990: 24-49). 


\section{References}

Cheng, Shui-Cheng 1979. The Role of the Traditional Musician in China, The World of Music, No. 2: 85-95.

Chinese Music Research Institute 1991. "An Introduction to National Music" (Zhongguo Yinyue Kailun), $6^{\text {th }}$ ed. People's Music Publishing House, Beijing.

Colin, Mackerras 1975. The Chinese theatre in Modern Times: From 1840 to the Present Day, University of Massachusetts Press, Amherst.

Gao, Hou-Yong 1981. "Outline of Chinese Instruments Music" (Zhongguo Qiyue Kailun), People's Publishing House of Jiangsu, Nanjing

Han, Kuohuang and Mark, Lindy Li 1980. Evolution and Revolution in Chinese Music, collected in the Music of Many Cultures - An Introduction, ed. By Elizabeth May and forward by Mantle Hood, University of California Press.

Jiang, Mingdun 1991. "Study of Folk Songs of Han Nationality" (Hanzu Mingge Gailun), second ed. Music Press of Shanghai, Shanghai.

Jone, Stephen 1995. Folk Music of China: Living Instrumental Traditions, Clarendon Press, Oxford.

Kattner, Fritz 1964. The Music of China: A short Historical Synopsis Incorporating the results of Recent Musical Investigations, Ethnomusicology No. 8 (May): 121-27.

Kaufman, Walter 1967. Musical Notation of the Orient, Indiana University Press, Bloomington, London.

Kouwenhoven, Frank 1990a. Music Research in China: Signs of Change, Chime (Chinese Music Europe), No. 1 (Spring): 51-8.

Kouwenhoven, Frank 1990b. Chinese Music Research in Europe: West meets West, Chime (Chinese Music Europe), No. 1 (Spring): 5-9.

Kouwenhoven, Frank 1990c. Organisations in China and abroad: A Bird's Eye View, Chime (Chinese Music Europe), No. 1 (Spring): 36-9.

Liang, Mingyue 1980. Music of the Billion - An Introduction to Chinese Musical Culture, Heinrichshofen Edition. New York.

Liu, Ji-Dian 1993. "Introduction to Beijing Opera_Music" (Jingju Yinyue Gailun), People's Music Publishing House, Beijing.

Liu, Tsunyuen 1978. Introduction to the Traditional Music of China, The World of Music, No. 2: 36-9.

Nettl, Bruno 1964. Theory and Method of Ethnomusicology, University of Illinois Press, Urbana.

Nettl, Bruno 1983. The Study of Ethnomusicology: Twenty-Nine Issues and Concepts, University of Illinois Press, Urbana and Chicago.

Pichen, Laurence 1957. The Music of Far Eastern Asia, 1: China, In the New Oxford History of Music, 1: Ancient and Oriental Music, ed. By Egon Wellesz, pp 83-134, Oxford University Press, London. 
Sadie, Stanley 1980. The New Grove Dictionary of Music and Musicians, vol.

4. China: 245-83, text by Rulan Chao Pian, Shigeo Kishibe, Colin P.

Mackerras, Kate Stevens, Bell N. Yung, Liang Mingyue, Tsunyuen Liu, A.C. Scott.

Song, Da-Neng 1979. "General Introduction to Folk Songs" (Minjian Gequ Gailun), People's Music Publishing House.

Thrasher, Alan 1985. The Role of Music in Chinese Culture, The World of Music, vol. Xxvii, No. 1: 3-7.

Wong, K. F. Issabel 1990. From Reaction to Synthesis: Chinese Musicology in the Twentieth Century, published in Comparative Musicology and the Anthropology of Music, ed. By Bruno Nettl and Philip Bohlman, University of Chicago Press: 37-55.

Wu Jun-Da 1988. "Study on the Vocal Music of Kunqu Opera" (Kunqu Changqiang Yanju), People's Music Publishing House.

Wu, Zhao and Liu, Dong-Sheng 1983. "Abbreviation of Chinese Music History" (Zhongguo Yinyue Shilue), People's Music Publishing House, Beijing.

Xia Ye and Chen Ying-Shi 1989. "Compendium of Chinese Music" (Zhongguo Minzu Yinyue Daxi), ed. Eastern Music Association (dongfang Yinyue Xuehui), Music Press of Shanghai, Shanghai.

Yang, Yin-Liu 1981. "The History of the Chinese Ancient Music (Zhongguo Gudai Yinyue Shi), People's Music Publishing House, Beijing.

Ye, Dong 1983. "The Form and Structure of Chinese Instrumental Music" (Minzu Qiyue De Ticai Yu Xingshi), Shanghai Arts and Literature Press, Shanghai.

Yuan, Jing-Fang 1987. "Chinese Instrumental Music" (Minzu Qiyue), People's Music Publishing House, Beijing.

Zhang, Wei-Hua 1985. Global Update: Recent Developments of Ethnomusicology in China. Ethnomusicology, vol. 29 No. 2 (spring/summer): 264-71. 